\title{
MINAT BELAJAR MAHASISWA PGSD PADA MATA KULIAH KONSEP DASAR IPA (Penelitian Deskriptif Kualitatif di Prodi PGSD Universitas Muhammadiyah Tasikmalaya)
}

\author{
Mohammad Fahmi Nugraha \\ Universitas Muhammadiyah Tasikmalaya \\ Jl. Tamansari Km. 2,5 Kota Tasikmalaya \\ E-mail : m.fahminugraha@umtas.ac.id \\ Budi Hendrawan \\ Universitas Muhammadiyah Tasikmalaya \\ Jl. Tamansari Km. 2,5 Kota Tasikmalaya \\ E-mail : hendrawan_budy@umtas.ac.id
}

\begin{abstract}
This study aims to determine the learning interest of PGSD Study Program students in the subject of basic social studies concepts. Qualitative descriptive research method with a case study approach, according to Kumar (1999) case study research is an approach to examine social phenomena through analysis of individual cases completely and thoroughly and provide an intensive analysis of many specific details that are often overlooked by other research methods. Whereas according to Pollit and Hungler (1999) interpreting case studies as research methods that use in-depth analysis, which is carried out completely and thoroughly on an individual, family, group, institution, or other social units. The results showed that PGSD students' interest in learning in basic science concepts was low, the results of the documentation study on the UTS value of the basic science concept subjects and interview results explained that there were several factors that influenced the low interest in student learning, namely student education background, teaching ability, weighting and subject matter of basic concepts of science, facilities to support lectures and lecture schedules.
\end{abstract}

Keyword:

Interest in learning; PGSD students; basic concepts natural science

\begin{abstract}
Abstrak
Penelitian ini bertujuan untuk mengetahui minat belajar mahasiswa Prodi PGSD pada mata kuliah konsep dasar IPS. Metode penelitian deskriptif kualitatif dengan pendekatan studi kasus, menurut Kumar (1999) penelitian studi kasus adalah suatu pendekatan untuk meneliti fenomena sosial melalui analisis kasus individual secara lengkap dan teliti, serta memberikan suatu analisis yang intensif dari banyak rincian khusus yang sering terlewatkan oleh metode penelitian lain. Sedangkan menurut Pollit dan Hungler (1999) memaknai studi kasus sebagai metode penelitian yang menggunakan analisis mendalam, yang dilakukan secara lengkap dan teliti terhadap seorang individu, keluarga, kelompok, lembaga, atau unit sosial lain. Hasil penelitian menunjukan minat belajar mahasiswa PGSD pada mata kuliah konsep dasar IPA rendah, hasil studi dokumentasi pada nilai UTS mata kuliah konsep dasar IPA dan hasil wawancara menerangkan ada beberapa faktor yang mempengaruhi rendahnya minat belajar mahasiswa yaitu latar belakang pendidikan mahasiswa, kemampuan dosen pengampu, bobot dan materi mata kuliah konsep dasar IPA, sarana penunjang perkuliahan dan jadwal perkuliahan.
\end{abstract}

Kata Kunci:

Minat belajar; mahasiswa PGSD; konsep dasar IPA 


\section{A. PENDAHULUAN}

Di Fakultas Keguruan dan Ilmu Pendidikan Universitas Muhammadiyah Tasikmalaya khususnya Program Studi Pendidikan Guru Sekolah Dasar minat belajar mahasiswa masih kurang tinggi, khususnya pada mata kuliah konsep dasar IPA. Hal ini dapat dilihat dari banyaknya mahasiswa semester I yang mendapat nilai Ujian Tengah Semester (UTS) rata-rata di bawah C meskipun ada beberapa mahasiswa yang mendapat nilai $\mathrm{B}$ dan $\mathrm{A}$.

Oleh karena itu penulis merasa tertarik untuk meneliti tentang "Minat Belajar Mahasiswa PGSD FKIP Universitas Muhammadiyah Tasikmalaya pada Mata Kuliah Konsep Dasar IPA".

Adapun masalah-masalah yang diidentifikasi adalah sebagai berikut.

1. Minat belajar mahasiswa PGSD FKIP UMTAS masih kurang khususnya pada mata kuliah konsep dasar IPA.

2. Nilai UTS mahasiswa pada mata kuliah konsep dasar IPA rendah.

Agar permasalahan tersebut dapat mencapai tujuan yang diinginkan, penulis perlu membatasi permasalahan penelitian.Adapun pembatasan penelitian ini adalah sebagai berikut.

1. Peneliti menjadikan mahasiswa PGSD semester 1 di Universitas Muhammadiyah Tasikmalaya sebagai responden dalam minat belajarnya pada mata kuliah konsep dasar IPA.

2. Penelitian dilakukan dengan menggunakan metode penelitian deskriptif kualitatif.

Berdasarkan latar belakang tersebut, penelitian ini bertujuan untuk mengetahui dan mendeskripsikan minat belajar mahasiswa PGSD pada mata kuliah konsep dasar IPA.

\section{METODE PENELITIAN}

Penelitian ini menggunakan metode penelitian deskriptif kualitatif dengan pendekatan studi kasus, menurut Kumar (1999) penelitian studi kasus adalah suatu pendekatan untuk meneliti fenomena sosial melalui analisis kasus individual secara lengkap dan teliti, serta memberikan suatu analisis yang intensif dari banyak rincian khusus yang sering terlewatkan oleh metode penelitian lain. Sedangkan menurut Pollit dan Hungler (1999) memaknai studi kasus sebagai metode penelitian yang menggunakan analisis mendalam, yang dilakukan secara lengkap dan teliti terhadap seorang individu, keluarga, kelompok, lembaga, atau unit sosial lain.

\section{B. HASIL DAN PEMBAHASAN}

Peneliti melakukan wawancara tidak terstruktur kepada enam mahasiswa PGSD sebagai narasumber tentang minat mereka terhadap mata kuliah konsep dasar IPA yaitu kepada saudari Novi, Pipit Fitriani, dan Siti Nurdini yang merupakan mahasiswa PGSD dari kelas A sedangkan tiga narasumber berikutnya adalah Dina Herlina, Ririn Khaerunissa dan Siti Komariah Nurlela yang merupakan mahasiswa PGSD dari kelas B.

Dari hasil wawancara dengan narasumber peneliti mengambil beberapa pernyataan penting tentang minat belajar mahasiswa pada mata kuliah konsep dasar IPA yang diuraikan sebagai berikut :

1. Hasil wawancara dengan narasumber pertama

(Novi Mahasiswi PGSD Kelas A) mengungkapkan bahwa dirinya memiliki latar belakang jurusan Ilmu Pengetahuan Sosial sehingga mempengaruhi minat belajarnya khususnya pada mata kuliah Konsep Dasar IPA, berikut pernyataannya "Saya kurang begitu minat pada mata kuliah konsep dasar IPA karena saya memiliki latar belakang dari IPS," selain faktor latar belakang pendidikannya Novi menyebutkan bahwa proses pembelajaran dilakukan dengan cepat dan hanya satu arah saja dengan menggunakan metode ceramah tanpa adanya diskusi.

2. Sebagai mahasiswa yang memiliki latar belakang IPS Novi menyarankan kepada dosen yang memberikan mata kuliah Konsep Dasar IPA untuk memberikan penilaian bukan hanya dari kemampuan dan ujian-ujian saja tetap keaktifan juga harus dimasukkan ke dalam kriteria penilaian.

3. Hasil wawancara dengan narasumber kedua (Pipit Fitriani Mahasiswa PGSD Kelas A) menerangkan bahwa meskipun dirinya berasal dari jurusan IPA namun tidak begitu memahami materi yang diajarkan karena menurut Pipit materi IPA itu harus didukung dengan adanya praktikum, berikut pernyataannya "Materi yang diberikan sangat banyak sehingga membuat saya jenuh, selain itu penyampaian materi dari dosen sangat 
cepat sehingga sulit untuk saya serap", selain penyampaian materi dan proses pembelajaran yang dinilai terlalu cepat dan jenuh Pipit menerangkan pengawas saat ujian pun mempengaruhi karena menurutnya jika diawas oleh dosen pengampu langsung akan membuat dirinya lebih fokus dalam mengerjakan soal ujian dan nilai yang akan didapat mungkin $90 \%$ nilai murni dari hasil mahasiswa itu sendiri.

4. Pipit berharap semester selanjutnya ada penambahan jam khusus untuk praktikum khususnya untuk mata kuliah konsep dasar IPA, "Kalau bisa ingin ada praktikum di laboratorium dan bobot sks nya di tambah supaya penyampaian materi bisa lebih maksimal," harapnya.

5. Hasil wawancara dengan narasumber ketiga (Siti Nurdini Mahasiswa PGSD Kelas A) memberikan pernyataan senada dengan narasumber sebelumnya, Siti berasal dari jurusan IPA namun pada mata kuliah konsep dasar IPA dirinya mengaku masih banyak yang harus diperbaiki, berikut pernyataannya "Menurut saya penyampaian untuk mata kuliah konsep dasar IPA sangat kurang waktunya sehingga membuat dosen menjelaskan sangat cepat karena untuk mengejar penyampaian materi selanjutnya," menurut Siti selain bobot sks yang kurang juga faktor yang lainnya adalah tidak adanya praktikum sehingga membuat dirinya mudah jenuh.

6. Siti menerangkan bahwa mata kuliah konsep dasar IPA sangat penting sehingga dia berharap ke depannya terjadi perubahanperubahan baik pada proses pembelajarannya maupun saran dan prasarananya. Hasil wawancara dengan narasumber keempat (Siti Komariyah Nurlela Mahasiswi PGSD Kelas B) menurut Siti meskipun dirinya berasal dari jurusan IPS namun tidak mempengaruhi proses pembelajarannya, berikut pernyataannya, "Menurut saya jurusan ketika SMA tidak berpengaruh, itu tergantung dari bagaimana mahasiswa menyikapinya saja, saya sendiri berasal dari IPS namun karena saya ada niat untuk belajar Alhamdulillah saya mendapat nilai A," selanjutnya Siti mengeluhkan akan waktu perkuliahan pada siang hari karena selain cuaca panas ditambah dengan materi yang disampaikan terlalu banyak membuat dirinya tidak konsentrasi dalam menyerap ilmu, "Waktu siang cuaca semakin panas dan mempengaruhi kenyamanan, gerah dan materinya banyak sehingga membuat saya cepat merasakan kantuk dan mengakibatkan kurang fokus dalam menerima materi," namun demikian Siti memiliki trik khusus untuk menyiasati masalah tersebut yaitu dengan menulis intisari setiap materi yang disampaikan, "Saya selalu menyalin kembali materi yang disampaikan dan menghafal materi tersebut dua jam setiap satu minggu," terangnya.

7. Selain memiliki inisiatif belajar mandiri, Siti berharap ke depannya ada perbaikanperbaikan sehingga proses pembelajaran mata kuliah konsep dasar IPA dapat berjalan dengan maksimal, "Saya ingin ada laboratorium khusus IPA agar bisa melakukan praktikum dan tidak hanya membayangkan saja selain itu ingin ada penambahan jam kuliah sehingga dalam penyampaian materi tidak terburu-buru," harapnya.

8. Hasil wawancara dengan narasumber kelima (Ririn Khaerunnisa Mahasiswa PGSD Kelas B) menerangkan bahwa mata kuliah konsep dasar IPA memiliki materi yang banyak namun dengan waktu yang sangat sedikit sehingga membuat Ririn menjadi mudah jenuh ketika proses perkuliahan berlangsung, berikut pernyataannya "IPA itu rumit dan banyak materinya namun waktu yang diberikan hanya sedikit sehingga sebelum masuk kelas saya selalu ada pikiran harus siap mengantuk ketika proses perkuliahan berlangsung," selain materi terlalu banyak dan waktu yang diberikan hanya sedikit Ririn menyebut faktor lainnya yang mempengaruhi adalah waktu perkuliahan yang dilakukan pada siang hari sehingga membuat kondisi tidak nyaman, "Waktu perkuliahannya siang jadi cepat gerah dan ngantuk," keluhnya.

9. MMenurut Ririn latar belakang jurusan ketika SMA tidak begitu berpengaruh karena menurutnya mata kuliah konsep dasar IPA merupakan mata kuliah dasar dan dimulai dari awal lagi, "Mau IPA ataupun IPS itu tidak berpengaruh, itu bagaimana kitanya saja kalau 
kita serius ya pasti akan bisa namun jika tidak serius ya tidak akan bisa," terangnya. Ririn berharap ke depannya disediakan fasilitas laboratorium dan penambahan waktu perkuliahan, "Saya ingin ada laboratorium IPA dan peralatannya untuk menunjang proses pembelajaran khususnya mata kuliah konsep dasar IPA," harapnya.

10. Hasil wawancara dengan narasumber keenam (Dina Herlina Mahasiswa PGSD Kelas B) yang menyebutkan dirinya bukan berasal dari IPA maupun IPS namun SMK Jurusan Teknik Komputer Jaringan (TKJ) sehingga mempengaruhi Dina dalam proses perkuliahan, berikut pernyataannya, "Saya berasal dari jurusan TKJ dan pada mata kuliah konsep dasar IPA itu materinya banyak dengan bobot 2 sks sehingga mau tidak mau penyampaian materi dalam satu pertemuan itu banyak," keluhnya, menurut Dina selain materi yang banyak dan waktu yang diberikan hanya sedikit juga faktor jadwal kuliah yang berada di siang hari sehingga mempengaruhi kondisi perkuliahan, "Waktu siang cuaca semakin panas dan mempengaruhi kenyamanan ketika menerima materi perkuliahan, merasa gerah, materi yang disampaikan banyak dan mengakibatkan mengantuk serta kurang fokus dalam pemahaman materi," ungkapnya.

11. Dina menyarankan kepada pihak lembaga untuk memberikan fasilitas laboratorium IPA sehingga materi yang disampaikan bisa diserap dengan maksimal jika dibarengi dengan praktikum, "Agar mahasiswa tidak merasa bosan dan jenuh diharapkan adanya fasilitas lab dan isinya, agar kita bisa melakukan praktek dan tidak hanya membayangkan dan diam di kelas pembelajarannya dan diharapkan ada penambahan sks agar materi tidak dipadatkan dalam 1 hari," harapnya.

12. Dari hasil penelitian dan studi dokumentasi berupa nilai UTS mahasiswa pada mata kuliah konsep dasar IPA dapat dijelaskan bahwa minat belajar mahasiswa masih kurang khususnya pada mata kuliah konsep dasar IPA, terlihat dari nilai UTS yang masih banyak mahasiswa yang memiliki nilai rendah didukung dengan hasil wawancara kepada enam narasumber dari keenamnya menyebutkan anggapan bahwa mata kuliah konsep dasar IPA merupakan mata kuliah yang rumit dan sulit dipahami sehingga minat belajar menjadi kurang, khusus di Program Studi Pendidikan Guru Sekolah Dasar Fakultas Keguruan dan Ilmu Pendidikan Universitas Muhammadiyah Tasikmalaya jadwal perkuliahan untuk mata kuliah konsep dasar IPA dilakukan pada siang hari yaitu pada jam 09.40 - 11.20 untuk kelas A dan pada jam 12.30 - 14.10 untuk kelas B sehingga beberapa mahasiswa mengeluh akan jadwal tersebut karena menurut mereka lebih baik jadwal mata kuliah konsep dasar IPA dilakukan pada pagi hari ketika kondisi masih segar dan mahasiswa dalam kondisi siap untuk menerima perkuliahan, berikut diuraikan faktor - faktor yang mempengaruhi minat belajar mahasiswa pada mata kuliah konsep dasar IPA :

13. Latar belakang jurusan mahasiswa sedikit banyak mempengaruhi minat belajarnya pada mata kuliah konsep dasar IPA karena ketika mahasiswa memiliki latar belakang jurusan IPA akan memudahkan dosen dalam penyampaian materi karena mahasiswa sudah memiliki dasar ketika dirinya berada di SMA/MA, apalagi untuk mahasiswa yang berasal dari SMK yang membutuhkan perhatian khusus dari dosen dalam penyampaian materi, namun demikian mahasiswa juga harus memiliki inisiatif dan trik khusus untuk menyiasati masalah tersebut.

14. Kemampuan dosen sangat berpengaruh karena pada mata kuliah konsep dasar IPA membutuhkan dosen yang cerdas mengendalikan situasi, mengajak mahasiswa untuk fokus selama perkuliahan dan melakukan perkuliahan dengan metode yang variatif dan dua arah.

15. Mata kuliah konsep dasar IPA memiliki bobot 2 SKS dengan materi yang sangat banyak dan padat yaitu terdiri dari 14 BAB yang membutuhkan waktu cukup panjang dalam proses penyampaiannya sehingga mau tidak mau dosen harus menyiasatinya dengan memadatkan materi dalam setiap pertemuannya. 
16. Ketersediaan sarana dan prasarana berupa laboratorium IPA dan peralatannya, karena dalam proses perkuliahannya ada materi yang harus dilakukan dengan praktikum, selama proses perkuliahan dosen hanya memberikan pemahaman kepada mahasiswa berupa gambar tanpa mahasiswa melihat langsung baik bentuk alat dan proses praktikum tersebut sehingga menyebabkan penyampaian materi sulit dipahami oleh mahasiswa.

17. Waktu perkuliahan juga berpengaruh, khususnya untuk kelas B yang memiliki jadwal perkuliahan siang hari yang membuat kondisi jadi tidak kondusif selain suhu meningkat juga kondisi mahasiswa yang menjadi tidak konsentrasi karena kondisi tersebut.

18. Kelima faktor tersebut merupakan masalahmasalah yang dihadapi oleh mahasiswa sehingga mempengaruhi minat belajarnya, khususnya dalam mata kuliah konsep dasar IPA, mata kuliah konsep dasar IPA merupakan mata kuliah keahlian program studi dan merupakan fondasi untuk mahasiswa karena mahasiswa di program studi PGSD disiapkan untuk menjadi pendidik di tingkat Sekolah Dasar yang wajib memiliki beberapa keahlian mata pelajaran (multi knowledge) baik IPA, IPS, Seni, Bahasa dan pelajaran lainnya selain itu apa yang diberikan selama perkuliahan akan menjadi bekal untuk mahasiswa ketika terjun ke lapangan baik ke dunia kerja maupun ke lingkungan masyarakat.

\section{SIMPULAN}

Hasil penelitian menunjukan minat belajar mahasiswa PGSD pada mata kuliah konsep dasar IPA rendah, hasil studi dokumentasi pada nilai UTS mata kuliah konsep dasar IPA dan hasil wawancara menerangkan ada beberapa faktor yang mempengaruhi rendahnya minat belajar mahasiswa yaitu latar belakang pendidikan mahasiswa, kemampuan dosen pengampu, bobot dan materi mata kuliah konsep dasar IPA, sarana penunjang perkuliahan dan jadwal perkuliahan.

\section{SARAN}

Penelitian lebih lanjut tentang minat belajar mahasiswa PGSD perlu terus dilakukan khususnya pada mata kuliah konsep dasar IPA agar proses pembelajaran dapat terus mengalami peningkatan setiap tahunnya karena mahasiswa PGSD disiapkan untuk menjadi seorang pendidik di tingkat Sekolah Dasar sehingga proses perkuliahan harus berlangsung dengan maksimal agar menghasilkan para pendidik yang berkualitas baik dalam segi pengetahuan dan kemampuan praktiknya.

\section{DAFTAR PUSTAKA}

Mukhtar. (2013). Metode Praktis Penelitian Deskriptif Kualitatif. JakartaSelatan : Referensi (GP Press Group).

Sugiyono. (2014). Metode Penelitian Kombinasi (Mixed Methods). Bandung : Alfabeta.

Achmad A, 2007, membangun motivasi belajar siswa, 22-23 diperoleh tanggal 14 November 2015 dari http://researchengines.com $\mathbb{T}$

B. Sidiq, 2012, Hakikat IPA, diperoleh tanggal 14 November 2015 dari http://eprints.uny.ac.id/8312/3/bab\%202\% 2008312244049.pdf

Djojosoediro, Wasih, 2012, Hakikat Ipa Dan Pembelajaran IPA SD, diperoleh tanggal 14 November 2015 dari http://pjjpgsd.unesa.ac.id/dok/1.Modul-1Hakikat\%20IPA\%20dan\%20Pembelajaran $\%$ 20IPA.pdf 